\title{
SOBRE LA NATURALEZA DE LA JUSTICIA INDÍGENA Y SU TRATAMIENTO EN EL ECUADOR: UNA EVALUACIÓN POST MONTECRISTI
}

\author{
Fernando Stalin Bajaña-Tovar \\ Universidad Católica de Santiago de Guayaquil
}

\begin{abstract}
Resumen: La naturaleza de la justicia indígena se ha mostrado generalmente como consabida en el contexto de la cultura jurídica ecuatoriana, predominando enfoques políticos que la identifican indiscriminadamente entre distintas categorías no siempre compatibles. La ausencia de un fundamento teórico que haya emanado exclusivamente de las ciencias jurídicas ha permitido la proliferación y encumbramiento de creencias reduccionistas dentro de la sociedad ecuatoriana, de modo tal que no son extrañas las interpretaciones antojadizas que observan en la institución in examine un estrago punitivo precolombino y una ópera marcada por el agua fría y la ortiga.

Ante esto, el presente ensayo pretende reexaminar críticamente las principales tesis que se han esgrimido sobre la naturaleza de la justicia indígena, a fin de demostrar las debilidades que se evidencian al momento de su aplicación; además de las negativas implicancias que han demostrado sus adopciones por los órganos estatales ecuatorianos.
\end{abstract}

Palabras clave: Justicia indígena. Grupos diferenciados. Sistemas sociales. Autopoiesis. Multiculturalismo liberal. Derecho de pueblos y comunidades. Pueblos indígenas. 


\title{
A post Montecristi review on the nature of indigenous justice and its treatment in Ecuador
}

\begin{abstract}
:
The nature of indigenous justice has generally been shown to be well known in the context of the Ecuadorian legal culture, with political approaches predominating that identify it indiscriminately between different categories that are not always compatible. The absence of a theoretical foundation that has emanated exclusively from the legal sciences has allowed the proliferation and elevation of reductionist beliefs within the Ecuadorian society, in such a way that the whimsical interpretations, that observe in the institution in examine, are not strange. Pre-Columbian punitive havoc and an opera marked by cold water and nettle.

The present essay intends to reexamine the main theses that have been advanced about the nature of indigenous justice, in order to demonstrate the weaknesses that are evident at the time of its application. In addition to the negative implications that have been demonstrated by their adoption by the Ecuadorian legal texts.
\end{abstract}

Keywords: Indigenous Justice. Differential Groups. Social Systems. Autopoiesis. Liberal Multiculturalism. Right of Peoples and Communities. Indigenous Peoples.

\section{Fernando Stalin Bajaña-Tovar}

Universidad Católica de Santiago de Guayaquil, Ecuador. Investigador adjunto del Departamento de Ciencias Sociales y Jurídicas de la Fundación Prometeo (UCSG- Fundación Prometeo). Estudiante de Derecho de la Facultad de Jurisprudencia y Ciencias Sociales y Políticas.

Correo electrónico: fbajana95@gmail.com; fernando.bajana@cu.ucsg.edu.ec 


\section{Introducción}

El espíritu inaugural del discurso político de la Constitución de Montecristi ${ }^{1}$ acerca de la reivindicación de grupos minoritarios e históricamente excluidos, degeneró en el campo fenomenológico en una apresurada identificación entre la letra constitucional y la reproducción material del Derecho. En este sentido, una atmósfera de interculturalidad presupuesta se mantiene casi intacta desde octubre de 2008, más aún cuando la Constitución abandona el clásico arquetipo liberal de Estado de derecho y se autodefine bajo el esquema de un Estado constitucional de derechos y justicia, social, intercultural y plurinacional. ${ }^{2}$

Este defecto de enfoque, que puede resumirse como la fe de creer a la problemática indígena - a propósito de la negación de sus derechos comunitarios y culturales-como disuelta a fuerza de promulgación legislativa, favoreció la repotenciación de una de las incorrecciones filosóficas menos novedosas en la esferas jurídicas latinoamericanas: la afirmación de la elaboración normativa como remedio potente para el allanamiento de conflictos humanos; esto es, la muy habitual anástrofe de la Guillotina de Hume en las culturas jurídicas regionales, según la cual es posible encontrar conclusiones fácticas acordes con la realidad a partir de premisas normativas.

Los antecedentes expuestos han provocado que los análisis propiamente jurídicos sobre la justicia indígena en el Ecuador, de forma especial aquellos derivados las instancias jurisdiccionales del Estado ecuatoriano, se encuentren gobernados por una serie de falacias circulares que declaran la evidencia absoluta del respeto al subsistema jurídico indígena a partir de su inclusión en los cuerpos normativos vigentes sin detenerse ni un solo instante

1 Nombre por el que se conoce a la «Constitución de la República del Ecuador» (2008), actualmente vigente, por el lugar donde funcionó la Asamblea Constituyente.

2 La Constitución señala textualmente: «Art. 1.- El Ecuador es un Estado constitucional de derechos y justicia, social, democrático, soberano, independiente, unitario, intercultural, plurinacional y laico. Se organiza en forma de república y se gobierna de manera descentralizada». 
en interrogar su naturaleza, siendo comunes los tratamientos dispersos que la identifican sin fundamento teórico alguno como derecho individual, competencia de grupo, sistema jurídico y rama jurisdiccional.

Esto ha significado para el derecho de los pueblos indígenas un desvalimiento de garantías institucionales que les aseguren la vida y la tutela de un modelo de justicia acorde con su cosmovisión cultural, y los proteja de las influencias hegemónicas de la maquinaría estatal, inspirada en los paradigmas clásicos de unidad y coordinación jurisdiccional. Cosa de lo más paradójica considerando que el propio sustrato normativo al que refieren los defensores de la eficiencia del interculturalismo ecuatoriano reduccionismo normativista-, manda y advierte la necesidad de aplicación de un sistema de garantías (jurisdiccionales, normativas, institucionales, etcétera) para la vigencia de los derechos constitucionales de los pueblos, nacionalidades y comunidades indígenas.

\section{Antecedentes filosóficos}

Sería errado entablar un tratamiento dogmático de la justicia indígena que no repase sus raíces, a fin de examinar la iluminación político-filosófica que lo fundó. En aras de esta tarea resulta obligatorio volver a entender al último decenio del siglo pasado, testimonio de la síntesis del debate políticofilosófico que las corrientes liberales y comunitaristas habían mantenido desde el siglo decimonónico, trabado con respecto a la admisibilidad de derechos subjetivos en favor de grupos humanos, lo que tácitamente implicaba el reconocimiento con la calidad de sujeto del derecho a un nivel organizacional distinto al psíquico. (Vázquez Luna 1998).

Esta superación hegeliana de la dicotomía liberal-republicana tradujo un ejercicio de consenso en virtud del cual las vertientes refractarias hallaron concilio bajo una nueva teoría, o conjunto de teorías para ser más exactos, conocida como multiculturalismo liberal (Sánchez Botero et al. 2009). Para Kymlicka (2009) la nueva corriente fue la responsable del asentamiento de las bases teórico-abstractas para la protección de intereses legítimos (culturales y comunitarios) en favor de colectivos humanos diferenciados, relativos a la conservación de sus lenguas maternas, la titularidad de territorios ancestrales, la capacidad auto determinativa y el autogobierno.

En palabras llanas, mediante el multiculturalismo liberal se rompió en el espectro filosófico el arquetipo ilustracionista, con su contrapartida civilista en el Derecho, debido al cual se certificaba exclusivamente con el atributo de persona a sustancias racionales individuales, entes públicos y sociedades mercantiles; haciéndolo extensible a grupos minoritarios, pueblos, nacionalidades y comunidades indígenas. 
Ahora bien, por ninguna razón debe entenderse que la aparición de la escuela multicultural constituyó el elemento distintivo para la eclosión de los derechos de grupos diferenciados, y menos aún para la adopción en los catálogos legislativos domésticos, toda vez que las contribuciones de esta vertiente filosófica se limitaron en gran medida a un plano intelectual, sin que trascendiesen de forma directa y amplia a lo político (Obieta Chalbaud 1985).

Así, Kymlicka (2009) demanda nuestra atención en el hecho que, si nos detenemos a analizar el entorno global en la misma fecha en la que las ideas multiculturalistas salían a la luz, hallaremos un concierto mundial que pasaba una suerte de transmutación de guerra fría a final de la historia y donde el ánimo pacifista inicial repentinamente era sustituido por el temor a un evento bélico con motivos étnicos a gran escala; lo que exige la atención y regulación de organismos internacionales. De esta manera la desovietización impulsada por Occidente, que en un principio movilizó una gran confianza en el modelo de democracia liberal como el sustituto perfecto y civilizado para el comunismo centralista y que se llegó a pensar como modelo universal, fue golpeada por una dosis de realismo que evidenciaba cómo con la desaparición del comunismo florecían conflictos entre las etnias ${ }^{3}$ que antes habían conformado la población de las extintas repúblicas socialistas, tratando imponerse una sobre otra con el de objeto de hacerse con el gobierno de las naciones refundadas. El propio Kymlicka sintetiza este acontecimiento magistralmente: «Predicciones exageradamente optimistas sobre la sustitución del comunismo por una democracia liberal, fueron suplantadas por predicciones pesimistas acerca de sustituir el comunismo con una guerra étnica (2009: 6).

Así fue como el riesgo inminente de una plaga de guerras étnicas en Europa, que empezaba a propagarse al resto del mundo, ${ }^{4}$ movió a la comunidad internacional a la creación de varias declaraciones y protocolos vinculantes, ${ }^{5}$ a través de los cuales se garantizó el amparo del Derecho Internacional Humanitario (DIH) a minorías étnicas y pueblos indígenas, reconociéndoseles la facultad de autogobierno y la administración de un sistema propio de derecho y justicia, en aras de apaciguar las luchas por la supremacía cultural que se libraban al interior de distintos estados; lo que involuntariamente transformó a estos grupos minoritarios en sujetos

\footnotetext{
3 Por ejemplo las guerras en el Este de Europa y la Península de los Balcanes, que tenía como fin imponer normas culturales de ciertos grupos sobre otros: Osetia, Chechenia, Bosnia y Kosovo

4 Uganda y Botsuana repetían la experiencia balcánica en África.

5 Como el Convenio 169 de la OIT y la Declaración de las Naciones Unidas sobre los Derechos de los Pueblos Indígenas.
} 
de derecho, soportando políticamente el aporte teórico de los filósofos multiculturalistas.

Por todo lo dicho, es apropiado afirmar que la concepción de la idea de derechos diferenciados de grupo como marco universal que engloba a la justicia indígena, es el producto de un encuentro accidental —en una misma época, pero con motivos diferentes- de dos procesos humanos independientes, uno intelectual y el otro político. Así, el multiculturalismo liberal como respuesta teórica a la necesidad de superar la incapacidad demostrada por las corrientes filosóficas decimonónicas para solucionar los problemas de un mundo post colonial (multiculturalismo, globalización, etcétera); encuentra un fructífero acople en las relaciones internacionales como herramienta inapreciable para el apaciguamiento de las luchas presentadas entre grupos humanos al interior de un Estado.

\section{Antecedentes normativos en el Ecuador}

En el caso particular del Ecuador, no fue sino hasta 1998 que se evidenció, con la promulgación de la decimonovena Constitución Política de la era republicana, ${ }^{6}$ la incorporación de los principales dispositivos normativos del Convenio 169 de la Organización Internacional del Trabajo (OIT) sobre pueblos indígenas y tribales - elemento fundamental del internacionalismo humanitario de fines del siglo XX-, incluyendo el derecho de los pueblos indígenas a administrar un sistema de justicia propio. La mencionada Carta Fundamental, en su artículo 191, establecía que:

[...] las autoridades de los pueblos indígenas ejercerán funciones de justicia, aplicando normas y procedimientos propios para la solución de conflictos internos de conformidad con sus costumbres o derecho consuetudinario, siempre que no sean contrarios a la Constitución y las leyes. La ley hará compatibles aquellas funciones con las del sistema judicial nacional (Constitución Política de la República del Ecuador 1998).

Alberto Wray Espinosa es muy crítico con respecto a los aparentes motivos que inspiraron la adopción de este campo regulatorio en el Ecuador, tachándolo de blando y carente de fundamento teórico individual, y como un resultado de la adopción de los protocolos internacionales que dotaban

6 La legitimidad de este texto constitucional no es aceptada por todos los autores ecuatorianos, debido a que nunca fue votada su aprobación en referéndum. 
a los pueblos indígenas, en su faceta de grupos humanos, de la titularidad de derecho. Así, el mencionado tratadista ecuatoriano sanciona que: «La justicia indígena, sin embargo, no existe como resultado de una decisión de política legislativa motivada en criterios técnicos o de eficiencia, sino que nace del reconocimiento de un derecho, cuyo titular es un ente colectivo: el pueblo indígena» (2002: 49). En este sentido, se aprecia que en el Ecuador la cabida de la justicia indígena dentro del orden coercitivo y tutelar aparece como producto de la sumisión a instrumentos internacionales - de orden general que no necesariamente rigen de forma integral el fenómeno indígena interno-, mas no a manera de política normativa motivada en la construcción intelectual doméstica.

No obstante, el alistamiento de la justicia indígena en la sección orgánica de la Constitución de 1998 destaca más por sus errores que por sus ventajas, principalmente en lo concerniente a la (i) indeterminación del sujeto titular del derecho y (ii) la contradicción de fondo que desarrolla el orden jurídico ecuatoriano a la hora de explicar la naturaleza de la institución in examine.

El primer punto, ha sido analizado a cabalidad por el precitado jurista ecuatoriano, quien por lo tanto considera que todo lo que se diga relativo al tema debe partir de sus observaciones. Para Wray el problema de indeterminación con respecto a quién es el titular del derecho a administrar el sistema de justicia indígena nace de la desacertada concepción de / Pueblo Indígena/7 ${ }^{7}$ que el artículo 83 de la Constitución de 1998 plantea en contravención de lo que establece el artículo 1 del Convenio 169 de la OIT.

El artículo del Convenio 169 de la OIT en mención conceptualiza en el artículo 1-b a los /Pueblos Indígenas/ como:

[...] pueblos en países independientes, considerados indígenas por el hecho de descender de poblaciones que habitaban en el país o en una región geográfica a la que pertenece el país en la época de la conquista o la colonización o del establecimiento de las actuales fronteras estatales y que, cualquiera que sea su situación jurídica, conservan todas sus propias instituciones sociales, económicas, culturales y políticas, o parte de ellas.

Destacando de dicha definición tres elementos de corte antropológico, a saber:

7 El criterio gráfico de barras simples "/xxxx /" está siendo empleado en el mismo sentido que adopta Umberto Eco en su obra Tratado de Semiótica General (1977), es decir para resaltar la calidad de significante de la palabra, por su parte las barras dobles "/xxxx/" se entenderán por significado. 
a) un elemento histórico: se trata de grupos humanos que descienden de poblaciones que habitaban el territorio ya en la época de la conquista o colonización; b) un elemento cultural: el grupo tiene entre sus características distintivas la conservación total o parcial de sus propias instituciones sociales, culturales y políticas; c) finalmente, un elemento de diferenciación psicosocial: la conciencia de su identidad indígena es lo que cohesiona al grupo y le sirve tan to para diferenciarse de otros como para relacionarse con los otros. (Wray 2002: 49)

Así las cosas, bajo la línea lógica de la norma supranacional expuesta, la categoría de / pueblo indígena/ se encuentra deslindada de toda referencia a elemento étnico alguno (entendido en el sentido genético), y se centra en tópicos culturales e introspectivos. En resumen, mediante el esquema semiológico que plantea el instrumento internacional de la OIT se faculta la correcta tutela de la autoconciencia singular que tienen sobre sí mismo los diversos grupos humanos que acceden a un universo etnológico común; lo cual permite, en consecuencia, que sea posible examinar la aptitud de /pueblo indígena/ a las distintas comunidades autodiferenciadas que coexisten al interior de una nacionalidad englobante y no a esta última supraestructura.

En el caso contrario se presentaría una enorme dificultad práctica a la hora de organizar la administración de la justicia indígena y ejercer la titularidad de los demás derechos diferenciados de grupo, puesto que se requeriría del consenso de todas las agrupaciones diferenciadas que constituyen una etnia o nacionalidad para la creación de una autoridad jurisdiccional étnica que los ordene; lo cual, si se estiman las relaciones no siempre armónicas que se manifiestan entre la poblaciones concurrentes, se vislumbra como casi imposible. A esto se agrega que la elección de una autoridad étnica, en vez de autoridades comunitarias, traduciría el allanamiento de la diversidad costumbrista y jurídica propia de cada población, que a diferencia de lo que se cree difieren mucho una de otra.

Empero, pese a las consecuencias negativas estudiadas relativas a la adopción de una definición de /pueblos indígenas/ donde prepondere el factor étnico, la Constitución del Ecuador de 1998 acogió ese sentido, precisando en su artículo 83 lo siguiente: «Los pueblos indígenas, que se autodefinen como nacionalidades de raíces ancestrales [...]». Esta exigencia, señalaría Wray, «[...] impide considerar a cada comunidad indígena como titular de los derechos colectivos, a menos que en dicha comunidad se agote la nacionalidad en cuestión». (2002: 50); y, en ultima ratio, genera un alto grado de indeterminación conceptual sobre el sujeto de la titularidad a la administración de justicia indígena, gravando aquel con inutilidad. 
Por otra parte, en lo que concierne a la contradicción de fondo que evidenció la legislación ecuatoriana para explicar la naturaleza de la justicia indígena, esta nace como producto de una premisa orgánica constitucional posteriormente adoptada por la legislación inferior. Al efecto, como pudimos observar previamente, los antecedentes filosóficos e internacionalistas que infundieron la adopción del Convenio 169 de la OIT, aunque no coincidan en sus motivos - superación filosófica y pacificación de conflictos étnicos internacionales-, retrataban las libertades autodeterminativas de los pueblos indígenas como «derechos diferenciados de grupos», esto es, como un derecho subjetivo o una «prerrogativa individual que la persona-sujeto extrae, separa de la norma jurídica» cuyo titular eran los pueblos indígenas (Ochoa 2006: 89).

Sin embargo, la Constitución de 1998 a pesar de hallarse inspirada en la norma supranacional referida, dedicó para el desarrollo de la justicia indígena la sección orgánica de la Constitución, específicamente el título VII relacionado con el poder judicial, lo cual resulta contradictorio con el «sentido político-material procedente del constitucionalismo, que definía las constituciones por su contenido: regulación de la frame of government (parte orgánica) y reconocimiento de los derecho subjetivos (parte dogmática)» (Fernández Sarasola 2002: 75). Como consecuencia del tratamiento de los derechos subjetivos en favor de los pueblos indígenas dentro del aparato estatal, la justicia indígena en el Ecuador quedó plagada dogmáticamente de un matiz orgánico jurisdiccionalista, que tal como se argumentará más adelante, es dañino para los principios de un Estado Moderno.

De estos dos puntos, (i) la indeterminación del sujeto titular del derecho a administrar el sistema de justicia indígena, y (ii) la contradicción de fondo entre derecho subjetivo y. aparato estatal en el tratamiento orgánico que la Constitución de 1998 le da a este derecho; la Constitución de 2008 significó una superación relevante desde una perspectiva normativa y teórica, excluyéndose ambas problemáticas del volumen de sus disposiciones. No obstante, aquello no significa que los problemas dogmáticos hayan desaparecido del tratamiento constitucional ecuatoriano, sino que los que existen en la actualidad se deben mayormente al accionar de los organismos públicos y no al contenido de sus normas.

\section{Conceptualización de la justicia indígena}

La información que hasta el momento se ha brindado, más allá de hacernos conocer que la justicia indígena en el Ecuador fue tratada por largo tiempo indistintamente como un derecho de un grupo diferenciado y como un 
orden jurisdiccional especial, no ha dado respuesta a las principales interrogantes que deben plantearse: ¿qué es la justicia indígena? y ¿a qué nos referimos cuando hablamos de un derecho diferenciado de grupo o un orden jurisdiccional especial? En lo que atañe, la respuesta al primer cuestionamiento se esquematizará inmediatamente, mientras que la contestación al segundo planteamiento se abordada a posteriori, ya que forma parte sustancial de la explicación de las teorías que explican la naturaleza de la justicia indígena.

Primero, debe quedar claro que no existe un consenso sobre la noción de justicia indígena, ni siquiera sobre el nombre que debe dársele. ${ }^{8}$ Ergo, las definiciones que han buscado precisar el contenido semántico de esta institución, para efectos pedagógicos pueden agruparse en dos grupos: (i) las definiciones dogmáticas, que identifican a la justicia indígena con un derecho fundamental de los pueblos indígenas; y (ii) las jurisdiccionales o procesalistas, que la explican bajo principios y dominios del Derecho Procesal. A estos se agrega una nueva noción en la que se profundizará: (iii) la posibilidad de meditar la justicia indígena como un subsistema social, tesis a la que llamaremos sistemática u organizacional.

En relación con la exigencia de conceptualización presentada ut supra, por el momento, se tomará una enunciación más o menos ecléctica, suficiente para continuar con la presente exposición sin que se comprometan doctrinalmente las conclusiones en lo que refiere al debe ser de la naturaleza de la justicia indígena. Así, por ahora, diremos que bajo el rótulo de justicia indígena se ha denotado a «los sistemas de normas, procedimientos $\mathrm{y}$ autoridades, que regulan la vida social de las comunidades y pueblos indígenas, y les permiten resolver sus conflictos de acuerdo a sus valores, cosmovisión, necesidades e intereses» (Yrigoyen 1999: 1).

Tal como se advierte, la definición de Yrigoyen encierra de una manera involuntaria las tres principales tesis que habíamos previsto: dogmatismo, pues el autor habla de la permisión normativa de resolver sus conflictos; procesalismo, en cuanto se sostiene en un esquema de procedimientos y autoridades; y organizacionalismo, al comparar la justicia indígena con un sistema de normas. Cada una de estas tesis se estudiará con detenimiento a continuación.

8 Este sistema en ocasiones es conocido como derecho mayor, justicia tradicional, derecho consuetudinario, derecho originario y ley indígena. 


\section{Naturaleza}

\subsection{Justicia indígena como derecho diferenciado de grupo}

Aguirre Sala (2014) instruye a los derechos diferenciados de grupo como medios «para proteger de la dominación a sujetos que pertenecen a identidades (probablemente minoritarias, pero no necesariamente así) en circunstancias de opresión» (2014: 91). Para la justificación de su postura, Aguirre Sala empieza desde los estudios de Iris Young referentes a la imprescindible dualidad de los sistemas jurídicos en los estados modernos, donde conviven obligatoriamente un sistema generalizado de Derecho que admite libertades iguales para todos sus ciudadanos, y un sistema específico «de políticas y derechos con conciencia de grupo, donde estos últimos son diferenciados» (2000: 92). Por consiguiente, el segundo sistema jurídico se habilitaría en la normativa coercible de los estados modernos con el único fin de garantizar la protección de aquellos grupos humanos que la tradición del sistema cultural predominante y su propia autoexploración reputan como desiguales (Sánchez Botero et al. 2009).

Pese a esto, debemos apartarnos de la pendiente resbaladiza de creer que la simple presencia de un sistema jurídico generalizado traduce opresión o hegemonía ${ }^{9}$ hacía un grupo minoritario; de ahí que, las cinco caras de la opresión de Young, nos facilitarán identificar la presencia o no de figuras represivas mediante un ejercicio de comprobación de variables pentagonales: explotación, violencia, violencia cultural, carencia de poder y marginación (De Donpablo 2012).

Para el efecto, la variable de explotación se comprobará cuando «el beneficio del trabajo de una persona es aprovechado por otra sin ningún tipo de recompensa para quien trabajó» (Aguirre Sala 2014: 92); en contrapartida, la presencia de marginación traduce la existencia de un fenómeno social de exclusión por medio del cual se privará al grupo diferenciado de manera progresiva de toda decisión política sobre asuntos que le conciernan. Luego, la carencia de poder cultivará un ambiente de indefensión donde el grupo humano para que se estime como oprimido deberá carecer de medios legítimos —otorgados o garantizados por el ordenamiento jurídico-para

9 Para Iris Young el concepto de opresión equivale a: «Profundas injusticias que sufren algunos grupos como consecuencia de presupuestos y reacciones a menudo inconscientes, que en las interacciones corrientes tiene buenas intenciones, y como consecuencia también de estereotipos originados de manera muy diversa, de las jerarquías burocráticas y los mecanismos del mercado; en síntesis, consecuencia de los procesos normales de la vida cotidiana que impiden sistemáticamente a los individuos de un grupo auto desarrollarse» (2000: 75). 
su defensa y protección de sus derechos, ante lo cual, cualquier reclamo proveniente de dicho colectivo humano será reprimido por la cultura hegemónica en nombre de la conservación del orden público; idea semejante engloba la violencia cultural, la misma que «funciona como una adjetivación calificativa que hace invisible y sin capacidad de evolución al sujeto que recibe la denominación estereotipante» (Aguirre Sala 2014: 92). Finalmente, las cinco caras de la opresión de Young terminarán con una variable de violencia propiamente dicha, avizorada como la práctica, generalmente impune, de acoso y hostigamiento en contra de un grupo oprimido (Aguirre Sala 2014).

De lo expuesto se colige que las variables de Young son mensurables a partir de criterios económicos y sociológicos. Por ello, la opresión de las poblaciones indígenas ecuatorianas que determinen la necesidad de su amparo bajo la mecánica de los derechos diferenciados de grupo deberá obedecer a la constatación de indicadores que evalúen esta percepción. A propósito de esto, los datos arrojados por el Sistema Integrado de Indicadores Sociales del Ecuador a partir de las encuestas del Instituto Nacional de Estadísticas y Censos (INEC) sobre condiciones de vida en los años 2006 y 2008 demuestran que las poblaciones indígenas en el Ecuador en un porcentaje del $89.2 \%$ adolecen de necesidades básicas insatisfechas; un 69.8\% se hallan inmersas en la pobreza medida desde el poder de consumo; un $86.8 \%$ carecen de servicios residenciales; un $39.1 \%$ se reputan analfabetos funcionales; y la media de escolaridad en sus comunidades apenas llega a los 4.2 años (INEC 2006; INEC 2008). Esto, contrastado con lo señalado en el párrafo anterior, da un resultado positivo en el test Young de opresión, lo cual justificaría la adopción de un modelo de derechos diferenciados de grupo.

Ahora bien, si bien las caras de la opresión siempre se han reputado como efectivas para el descubrimiento de sistemas abusadores, estas han sido criticadas por su propensión a sesgos económicos, ante lo cual Aguirre Sala (2014) descubre en las afrentas morales postuladas por Honneth (1996) un esquema interesante de compaginar, con el fin de constatar una real opresión que no se agote en ámbitos infraestructurales:

Podemos agregar a esta breve fenomenología de la opresión cada uno de los agravios morales provocados por las respectivas faltas de reconocimiento tan denunciadas por Honneth, podemos aumentar una primera herida en el maltrato de la persona (Vergewaltigung) como un acto que ataca su integridad física y psíquica; agravio que terminará por arrebatarle su autonomía. Un segundo agravio en el menosprecio que priva de derechos (Entrechtung) y excluye a las personas de su condición jurídica. Y una tercera herida, cuando se 
desvaloriza el modo de vida de un individuo singular o de un grupo, al provocar la degradación o deshonra (Entwürdigung) o la carencia de dignidad. [...] se ha nominado el cuarto tipo de agravio moral (Indiferencia/Gleichgültigkeit) que correspondería al cuarto tipo de reconocimiento (política de identidad) [...] (Aguirre Sala 2014: 92).

Ante lo cual, lo dicho por la Organización de las Naciones Unidas para la Infancia (Unicef,) y el Ministerio Coordinador de Patrimonio del Ecuador (2010) con respecto al hecho de que es posible constatar aún en la sociedad ecuatoriana la presencia de mecanismos de exclusión social idénticos a los utilizados contra los pueblos indígenas en la poca colonial aunque con estratagemas encubiertas, pero que de igual forma siguen privando a las poblaciones indígenas del pleno goce de los derechos fundamentales establecidos en la Constitución del Ecuador y el Plan del Buen Vivir, reporta una premisa concluyente para aseverar la opresión de los pueblos indígenas en el Ecuador, tanto desde una caracterización younguiana de relevancia económica, como desde un análisis moral al estilo de Honneth.

Ergo, como antes se dijo, los defensores del multiculturalismo liberal advierten frente a estos fenómenos de opresión la necesidad de adoptar un catálogo de derechos en favor de grupos humanos históricamente excluidos y que demandan la necesidad de ser reconocidos como sujetos de derecho propio o mejor dicho, individualizados, frente a la población hegemónica. Sánchez Botero y Jaramillo señalan: «Los pueblos indígenas, como se anotó anteriormente, constituyen un caso claro de aplicación de la teoría de los derechos de grupo: constituyen grupos que han reclamado un reconocimiento de su diferencia y esta diferencia es reconocida, a su vez, como valiosa» (2009: 132).

En este orden, Vázquez Luna (1998) define el derecho a la autonomía o libertad como el principal derecho diferenciado que deberá reconocerse a los pueblos indígenas; toda vez que, solo en virtud de este, los pueblos indígenas estarían facultados para emprender comunicaciones jurídico-políticas independientes que les permitan mantener viva su identidad grupal. Cabe destacar que esta libertad y autonomía podrá ser actuada en un sentido positivo o negativo. De esta manera, los derechos diferenciados permiten a los pueblos indígenas exigirle al Estado la seguridad de condiciones mínimas para la operatividad de sus comunicaciones y la abstención de cualquier tipo de intervencionismo asfixiante.

Surge finalmente, como una necesidad lógica, la idea de identificar a la justicia indígena con un derecho diferenciado y específico de grupo, que garantizaría a los pueblos indígenas la libertad para crear normas de Derecho e implementarlas para su autorregulación, según la cosmovisión y sustratos 
axiológicos que cada uno comparta. Esta es la noción de justicia indígena que ha sido acogida por la mayoría de las memorias internacionales de Derechos Humanos que tratan sobre la problemática (Vásquez Luna 1998).

Sin embargo, esta tesis sobre la naturaleza de la justicia indígena como derecho diferenciado de grupo no ha estado exenta de críticas, puesto que la asimilación de la justicia indígena con un derecho diferenciado adolece de una falta de independencia dogmática y en consecuencia depende de una continua referencia a conceptos de la filosofía política y normas positivas de tratados internacionales. De esta manera, esta tesis por sí misma sería incapaz de responder preguntas fundamentales para el ejercicio de este derecho, a saber: ¿quiénes son los sujetos titulares de la justicia indígena?, y de ser el caso ¿qué se entiende por un pueblo indígena ${ }^{10}$

\section{Figura 1.}

\section{Relación semántica entre /significante y //significado//}

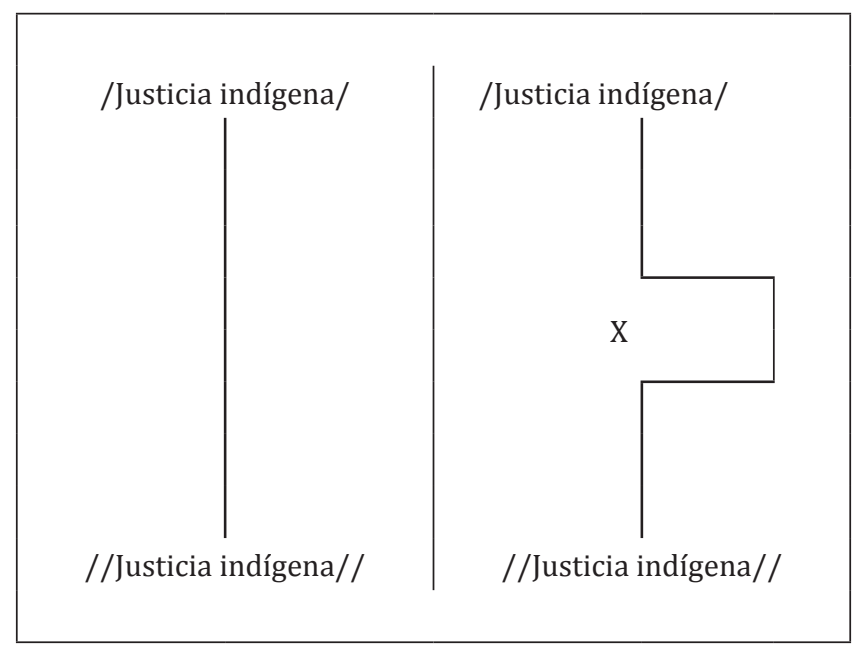

Leyenda: Se muestra un segmento A. donde la relación no es afectada por ningún tipo de obstáculo o ruido " $\mathrm{X}$ "; y un segmento B. donde se presenta el obstáculo de remisión a otros sistemas.

La figura 1 representa válidamente esta problemática, mientras que lo ideal sería una relación semántica como la configurada en el segmento $A$, donde el significante de /Justicia indígena/ se relaciona directamente con su

${ }^{10}$ Los teóricos del dogmatismo se han limitado generalmente a redireccionar los cuestionamientos a las definiciones de cuerpos legales, como la contenida en el Artículo 1 de la Convención 169 de la OIT, sobre pueblos indígenas y tribales, demostrando una evidente dependencia conceptual. 
significado //Justicia indígena//, mientras que el fenómeno que se ha presentado con la adopción de la tesis dogmática de derechos diferenciados de grupo, esto es, la figura del segmento $B$, generalmente ha presentado como problema una significación dependiente de la remisión a un texto legal o convencional $(x)$, lo cual, aunque pareciera a primera vista no establecer ningún obstáculo, en la práctica, debido al dinamismo de la técnica legislativa, provoca el debilitamiento y exposición de la relación semántica, en cuanto los textos legales o convencionales suelen ser cambiantes y subordinados a la decisión de los órganos estatales que administran los grupos humanos hegemónicos, lo que pone en riesgo a la supervivencia de los derechos indígenas. Todavía más, cuando el Ecuador ya ha atravesado una controversia semejante, donde el significante de /pueblo indígena/ sobre el cual recaía la titularidad de la justicia indígena fue alterado por una remisión a un dispositivo constitucional (x) -artículo 83- que interrumpía la comunicación natural y la redirigía hacia un significado inoperante, /nacionalidad indígena/.

La figura 2 muestra el problema de aplicación que se presentaba por la definición de pueblo indígena que contenía el artículo 83 de la Constitución de 1998, que lo asemejaba al concepto de nacionalidad. El obstáculo significativo está dado por dicho dispositivo constitucional " $\mathrm{x}$ ".

Finalmente, y agregando para la crítica, debe amonestarse a las tesis dogmáticas el hecho de que la identificación entre justicia indígena y derecho diferenciado le obliga heredar a la primera noción todas las objeciones esgrimidas en contra del multiculturalismo liberal, en especial en lo concerniente a la fórmula de ponderación entre derechos diferenciados de grupo y derechos individuales de sus miembros. Partiendo desde la noción de ambos sujetos de derechos, seguirían supeditados a los límites constitucionales de un Estado-Nación determinado.

[...] es importante destacar la relación entre los derechos de los pueblos indígenas y los derechos de las personas que pertenecen a estos pueblos. Puesto que los pueblos indígenas hacen parte de Estados independientes y no son ellos mismos Estados independientes, es importante para los miembros de los pueblos indígenas ser nacionales de los Estados en los que habitan. Como ciudadanos de estos Estados merecen ser tratados con igual consideración. Este tratamiento justo implica, por una parte, el reconocimiento a sus pueblos de derechos diferenciados de grupo. Por otra, el reconocimiento a los individuos, en tanto individuos, de los derechos que se conceden a los demás ciudadanos. En particular, es importante la garantía de la no discriminación por su pertenencia a grupos indígenas. (Sánchez Botero et al. 2009: 461). 
Figura 2.

Definición de pueblo indígena de la Constitución de 1998

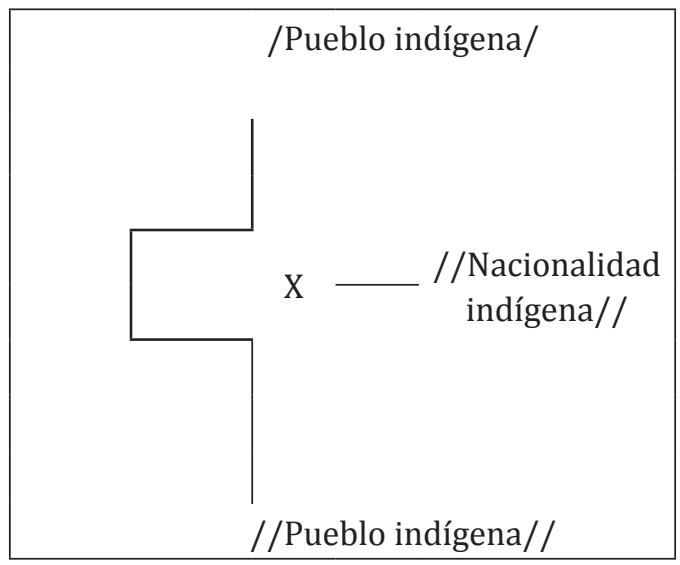

Leyenda: X= Artículo 83 de la Constitución de1998

Por todo lo expuesto, las tesis que identifican la naturaleza de la justicia indígena como un derecho diferenciado de grupo no deben ser adoptadas, al menos no sin antes oponer todas las excepciones analizadas, principalmente en lo versado sobre su falta de independencia conceptual y subordinación normativa. De ahí, que no es una de las mejores tesis para sostener por sí misma la validez y esencia de la justicia indígena; sin embargo, como se demostrará posteriormente, su concatenación con teorías sistémicas resultará muy provechosa.

\subsection{Justicia indígena como jurisdicción especial}

Otra de las teorías que ha bosquejado la doctrina y la jurisprudencia regional para analizar la naturaleza de la justicia indígena, es aquella que vincula sus principios, normas y reglas, con los principios y estructuras comunicacionales del Derecho Procesal. De esta forma, no han sido escasas las definiciones con esta inspiración las que se han patentado dentro de las normativas formales de los estados latinoamericanos.

Para esta corriente se entiende por justicia indígena, a «la potestad de los pueblos indígenas de recurrir a sus autoridades e instancias internas para dar solución a las controversias que se generen dentro de sus territorios, así como a la facultad de tomar decisiones, juzgar y ejecutar hechos de acuerdo con sus normas tradicionales» (Díaz Ocampo et al. 2016: 
25); lo que comprueba claros indicios de aculturación occidental, de modo que es innegable la influencia que causan sobre esta definición las doctrinas procesalistas liberales que largamente han caracterizado a la jurisdicción ordinaria como una «potestad de juzgar y hacer cumplir con lo juzgado» (Código Orgánico General de Procesos).

Bajo esta línea argumentativa, los autores procesalistas exigen a los pueblos indígenas como condiciones ineludibles para la administración jurisdiccional, a saber: (i) la existencia de autoridades; (ii) una circunscripción territorial demarcada; (ii) un conjunto de normas adjetivas propias; y, (iii) la sumisión a la Constitución y la ley (Díaz Ocampo et al. 2016). ${ }^{11}$ Esto significaría un empuje para la adopción de nociones clásicas del lenguaje del sistema jurídico predominante, en el seno de las prácticas indígenas.

Lo grave del asunto es que, bajo los supuestos referidos, la omisión de uno de los requisitos precitados implicaría la prohibición de administrar justicia en la estructura de justicia comunitaria (anulabilidad de la competencia), revelando una forma más de violencia cultural y carencia de poder que ya antes habíamos notado que denunciaba Young.

Por citar un ejemplo, un pueblo indígena no asentado cuya dieta dependa de la recolección de frutas y caza de animales, como sería el caso del pueblo indígena waorani en el Ecuador (Cabodevilla et al. 2004), por estar obligado al tránsito constante entre territorios disímiles, se vería simplemente impedido de ejercer funciones jurisdiccionales, por la imposibilidad de circunscribirle una competencia territorial fija tal como lo exigen las tesis jurisdiccionalitas.

De igual manera, de existir un pueblo indígena que no reconozca la estratificación jerárquica en sus habitantes, ya sea por estar sometidos a un comunitarismo sensible o a un régimen de división de pequeñas tribus o clanes que dificulta la correlación entre múltiples mandos y complica la designación de una autoridad natural, estarían inhibidos de la concepción de un juez natural, lo que les imposibilitaría la administración de justicia debido a la ausencia de una autoridad jurídica definida. Caso contrario, si dicha autoridad no fuera constante, y se eligiera de forma ulterior para el juzgamiento del problema surgido, conllevaría a un juzgamiento de excepción y al rompimiento del cuarto elemento de la propia doctrina procesalista, esto es, la supremacía de la Constitución y los Derechos Humanos, o en otras palabras del arquetipo de Estado de Derecho. ${ }^{12}$

Por las razones antepuestas, la presente tesis no ha trascendido en el ámbito internacional, más allá la esfera regional, estando escasamente

\footnotetext{
${ }^{11}$ Estos conceptos equivalen a los de: juez, competencia territorial, legalidad adjetiva, y supremacía constitucional.

12 Revisar el artículo 76 de la Constitución de la República del Ecuador.
} 
reproducida por el tribal law del derecho anglosajón y la justicia autonómica de la Unión Europea. De ahí que lo más alarmante sea la fuerza que esta tesis aculturalizante y discriminatoria, ha demostrado para ser acogida en los tribunales constitucionales de mayor trayectoria en Sudamérica como Colombia y el Perú; e incluso, en las más altas jerarquías jurisdiccionales de aquellos países que adoptaron el neoconstitucionalismo andino en el primero decenio del siglo XXI, es decir, Ecuador y Bolivia.

Bajo esta línea argumentativa, sentencias constitucionales como la T-921/13 de la Corte Constitucional de Colombia, deben ser advertidas con cierta alarma y precaución. Dicha resolución establece:

Por otro lado, la Corte Constitucional consideró que la jurisdicción indígena comporta: (i) Un elemento humano, consistente en la existencia de un grupo diferenciable por su origen étnico y por la persistencia diferenciada de su identidad cultural; (ii) Un elemento orgánico, que implica la existencia de autoridades tradicionales que ejerzan una función de control social en sus comunidades; (iii) Un elemento normativo, de acuerdo con el cual la respectiva comunidad se rija por un sistema jurídico propio conformado a partir de las prácticas y usos tradicionales, tanto en materia sustantiva como procedimental; (iv) Un ámbito geográfico, de acuerdo con el que la norma que establece la jurisdicción indígena remite al territorio, el cual según la propia Constitución, en su artículo 329, deberá conformarse con sujeción a la ley y delimitarse por el gobierno con participación de las comunidades y; (v) Un factor de congruencia, en la medida en que el orden jurídico tradicional de estas comunidades no puede resultar contrario a la Constitución ni a la ley (Corte Constitucional de Colombia 2013).

De esto se colige que además de los tópicos ya criticados, como el elemento orgánico, autoridad tradicional y permanente; y el elemento geográfico, jurisdicción territorial; la sentencia in examine recoge la falacia etnológica para la determinación del fuero personal indígena, toda vez que, la existencia de un grupo humano cuya congruencia esté determinada por un origen étnico común - lo cual como analizamos anteriormente-contradice el enfoque que mantiene el Convenio 169 de la OIT, donde la carga indígena reside en la cultura y no en la etnia. Idénticamente es criticable la pretensión integracionista que ocupa a la justicia indígena en un lugar residual, puesto que en aras de proteger un elemento de congruencia (otra forma de llamar a los principios liberales de unidad jurisdiccional y coherencia normativa), subordina a las prácticas indígenas, no solo a la Constitución, sino a la ley, que 
como antes se dijo, generalmente es un mandato derivado de un órgano estatal (Congreso) que obedece las decisiones políticas de la población hegemónica.

Ahora bien, es cierto que han existido esfuerzos actuales para contrarrestar las pretensiones jurisdiccionalitas a través de la estandarización de una metanorma que los mismos órganos jurisdiccionales antedichos han esbozado, a saber, la máxima de interpretación intercultural, según la cual, «es obligación de toda autoridad ya sea administrativa o judicial que conocen un proceso sometido a su análisis, en el que uno o más de los sujetos intervinientes sean comunas, comunidades, pueblos o nacionalidades, resolverlo empleando criterios de interculturalidad, para de esta forma garantizar sus derechos de la forma que más satisfaga sus derechos. Así lo determinó la Corte Constitucional» (Corte Constitucional del Ecuador 2018).

Sin embargo, a pesar de aquello, no es menos cierto que el riesgo a la instauración de un pluralismo fáctico de exclusión mutua (Wray 2007) por parte de los estados sigue latente. Ya ha quedado demostrado este riesgo, por ejemplo, con la conocida sentencia No. 113-14-SEP-CC de la Corte Constitucional del Ecuador - Caso La Cocha-, mediante el cual se desconoció la prohibición del non bis in idem de un caso penal que previamente había sido resuelto por una autoridad indígena, argumentando que el bien jurídico protegido en los delitos contra la vida por parte de la justicia penal ordinaria no era el mismo que protegía la justicia indígena, por cuanto la sanción que había impuesto esta última había tenido como fin el de proteger el equilibrio y convivencia comunitaria y no el bien jurídico de la vida observado de forma individual, prohibiendo en consecuencia la resolución de controversias penales por parte de los pueblos indígenas, y argumentando:

«[... sin que pueda hablarse de interferencia ni de disminución del derecho de autonomía jurisdiccional de las comunidades, pueblos y nacionalidades indígenas, en caso de que ocurra un delito contra la vida dentro de una comunidad o territorio indígena, el Estado garantizará, al igual que en el resto del territorio nacional, que el mismo sea juzgado y sancionado de conformidad con las leyes propias del Derecho Penal Ordinario» (Corte Constitucional del Ecuador 2014).

En virtud de este riesgo, esto es, el de un ambiente de exclusión mutua entre los sistemas jurídicos coexistentes (indígena-no indígena) que degenere en un escenario de inseguridad jurídica y que inclusive desconozca principios jurídicos básicos como el non bis in idem; así como, la facilidad demostrada por los órganos jurisdiccionales tradicionales para allanar a su antojo las competencias en justicia que tendrían los pueblos indígenas, se concluye que teorías como estas, no son recomendables para su institucionalización en los estados modernos. 


\subsection{Una nueva tesis para explicar la naturaleza de la justicia indígena. ¿Los sistemas autopoiéticos?}

Sin que hasta ahora se haya alcanzado a través de un análisis crítico, al menos de uno honesto, una concepción clara de la naturaleza de la justicia indígena - tanto las tesis dogmáticas como las procesalistas adolecen de incertidumbre y dependencia-, decidimos impeler una nueva apuesta y proponer como el saldo más certero para entender al fenómeno de la justicia indígena, a la teoría de los sistemas sociales de Luhmann.

Niklas Luhmann (1987) afirma en su teoría sistémica que la sociedad es producida y reproducida a través de la comunicación. En esta medida, la comunicación y no la entropía, es «[...] una operación sistemática e ineluctablemente de carácter social que implica, al menos, dos socios cuyas acciones solo pueden ser constituidas por la comunicación» (Urteaga 2010: 306). En este sentido, Luhmann plantea que solo será posible la existencia de un sistema social en la medida en que este pueda autogenerarse mediante la reproducción de sus comunicaciones (conocimientos). Para nuestro caso, solo hablaríamos de un sistema socio-jurídico indígena autónomo, cuando aquel posea la aptitud de autorreferencia a partir de sus comunicaciones ancestrales (Duprat 1990).

De esta manera se critica la preocupación innecesaria de las ciencias políticas, la filosofía y la sociología antropológica sobre aspectos accidentales de la sociedad, tales como las distinciones étnicas, comunitarias y culturales; toda vez que, al igual que Sánchez Botero y Jaramillo, han expresado que considerar «que dos grupos de personas son diferentes, no es más que el resultado de privilegiar en nuestras prácticas sociales un parámetro de comparación» (2009: 130).

De este modo, cuando fundamentamos las teorías dogmáticas y procesalistas diciendo que los indígenas, en razón de su lengua, raza o territorio, son diferentes a la mayoría poblacional del Ecuador y por tanto constituyen un grupo social diferente (sistema humano diferenciado), obviamos declarar que consideradas otras variables, como la especie biológica, la nacionalidad estatal, y las prácticas económicas, los indígenas y la mayoría poblacional estarían incluidos en un mismo sistema social. Esto comprueba que este tipo de razones (étnicas, raciales, etcétera) forman parte de «diferenciaciones internas, que son secundarias a la hora de comprender la manera según la cual la sociedad actúa, se transforma y produce acontecimientos» (Urteaga, 2010: 307).

Por lo tanto, el criterio que debe ser utilizado para la distinción de un sistema social de otro, desde el paradigma de las sociedades modernas, debe ser exclusivamente funcional, entendido en un sentido matemático; puesto 
que precisamente un sistema social alcanzará su independencia (clausura autorreferencial) y la posibilidad de creación de subsistemas propios, incluyendo uno jurídico, cuando haya podido establecer su propio códigodiferencia binario (Luhman 1987).

Sobre este aspecto, Marcelo Neves sentencia que: «Por medio del código sistémico propio, estructurado binariamente entre un valor negativo y un valor positivo específico, las unidades elementales del sistema son reproducidas internamente y distinguidas claramente de las comunicaciones exteriores» (1996: 407).

Contrastando lo dicho con nuestra problemática, los pueblos indígenas constituirían sistemas sociales verdaderos solo conforme creen un esquema binario personal, que le permita diferenciarse de su entorno. Desde aquí las comunicaciones reconocidas bajo el código indígena/sistema prevalecerían sobre el código hegemonía/entorno.

Manteniendo esta línea argumentativa, Luhmann (1973) recomienda, movido por la teoría biológica de Maturana, la clausura operativa del sistema social, descartando la posibilidad de sistemas abiertos y los mecanismos de neguentropía de Bertalanffy (Aragón 2011). No obstante, la clausura recomendada por Luhmann, no se entiende desde un aspecto arquitectónico - cuarto cerrado - sino que tiene un carácter operativo, una suerte de remedo de la permeabilidad selectiva de las células, en virtud de la cual, como señala Neves,

[...] la combinación de cierre y de apertura puede ser tratada bajo dos perspectivas: (i) ya sea que un sistema constructor y construido a partir del sentido ejerza o "controle las propias posibilidades de negativa con ocasión de la producción de los propios elementos" (cierre); ese control depende de las condiciones de elección entre el sí y el no del respectivo código sistémico (apertura); (ii) o bien que el control de las posibilidades de negativa (clausura) proporciona una relación selectiva continua y estable (o, al menos, menos inestable) del sistema con su medio ambiente (apertura adecuada) (1996: 414).

De todo lo expuesto, se deduce la presente tesis como la más apropiada para la construcción de pueblos indígenas con autonomía gubernamental y jurisdiccional, pasando estos de ser meros sujetos de Derecho o administradores de justicia, según el caso, a verdaderos sistemas sociales de segundo orden. Claro que, sopesada la presente tesis con la realidad nacional ecuatoriana, se vislumbra todavía lejana la posibilidad de autorreferencialidad en nuestros pueblos indígenas, provocada principalmente por la serie de sesgos cognitivos que se abordarán más 
adelante y la predominación de elementos de premodernidad en nuestro Estado (Urteaga, 2010).

Empero, se continuarán exponiendo las ventajas de esta teoría, con el fin de aportar con un precedente ontológico que motive a su adopción, aunque solo sea en la esfera abstracta de la teoría.

\subsubsection{El subsistema jurídico Luhmanniano y su adopción para la justicia indígena}

Luhmann entiende los sistemas jurídicos como subsistemas funcionales que entrelazan comunicaciones codificadas al interior del complejo universo social. Cada subsistema a su vez sobreviviría debido a la configuración de un código binario exclusivo, siendo en el caso del Derecho uno que le permita distinguir entre lo jurídico/recht y lo antijurídico/unrecht (Montoro 2007).

Visto así, la plena vigencia del sistema de justicia indígena le demandaría a los pueblos ancestrales la capacidad de reglar expectativas normativas de conducta -Normative Erwartungen- (Luhmann 1973), las cuales deberán estar generalizadas en una proyección tridimensional: temporal, material y social; de tal manera que las expectativas normativas de los pueblos indígenas (i) permanezcan en el tiempo, ya sea que se reproduzcan o no; (ii) se institucionalicen por el consenso interno del grupo; (ii) y se describan desde la autorreferencia de sus contenidos ancestrales.

Empero, el sistema de justicia indígena adoptado por el Ecuador dista mucho de alcanzar el grado de evolución de un subsistema luhmanniano, principalmente por la carencia de pueblos indígenas ya establecidos como sistemas sociales autopoiéticos; lo que en la práctica traduce el impedimento para la producción de expectativas normativas autónomas, producto de las altas restricciones temporales y materiales fijadas por el monopolio estatal en materias de educación, cultura y economía.

Ejemplificando nuevamente, cada vez es más difícil concebir que la expectativa normativa de convivencia con la pachamama y la conservación del suelo permanezca intacta en las comunidades indígenas, si se advierte la marcada sobreposición del modelo extractivista estatal al agrícola indígena. De esta forma, el tratamiento de la tierra como propiedad privada (capitalización del suelo) y la proliferación del extractivismo ponen en riesgo la supervivencia de los valores ancestrales indígenas (Martínez et al. 2017); mucho más cuando en el Ecuador la Corte Constitucional en su sentencia No. 009-13- SIN- CC, les negó a los pueblos indígenas el carácter vinculante de las 
consultas prelegislativas, ${ }^{13}$ cuando se discutiera en el pleno de la Asamblea la explotación de recursos no renovables en sus territorios ancestrales.

Por lo antedicho se advierte aún como difícil la adopción de la teoría luhmanniana en el tratamiento de la justicia indígena en el Ecuador, con motivo de la serie de obstáculos normativos y prácticos que se han reconocido. No obstante, si por un momento optamos por dejar de observar la relación entre Estado y pueblos indígenas como de opresores y oprimidos, tal vez encontremos en dicha correspondencia antagónica rasgos de postmodernidad, y así replantear la autopoiesis a fin de que sea remplazada por una alopoiesis jurídica. En todo caso, esto se tratará más tarde; antes hará falta descifrar los principales problemas orgánicos y comunicacionales del tratamiento de la justicia indígena en el Ecuador.

\section{Tratamiento material de la justicia indígena en el Ecuador}

Dos son los principales problemas que presenta el tratamiento material de la justicia indígena en el Ecuador; por un lado, (i) el exceso de sesgos cognitivos que representan su identidad folclóricamente; y por otro, (ii) la falta de independencia comunicacional entre los subsistemas que integran la organización social de las poblaciones indígenas (Gómez 2000).

En lo que concierne al primer problema, Elosúa (1994) precisa como un fenómeno recurrente a lo largo de la historia republicana, la utilización de estereotipos - sesgos cognitivos - a la hora de describir aquello que implica una situación de interculturalidad. De tal forma, la cultura dominante busca la estereotipación y la implementación de prejuicios sociales, con el fin de fabricar correlaciones ilusorias que le permitan continuar con una diferenciación opresiva y beneficiosa para sus intereses.

Esa sería la razón por la cual el imaginario social en el Ecuador y en gran parte de los países de Latinoamérica, esté marcado por una percepción de la justicia indígena como reducto de vindictas públicas y discontinuidad temporal, o en otras palabras, de linchamientos y ancestralidad. (Mires 1992).

En lo relativo a la ancestralidad, uno de los principales obstáculos que han manifestado los sistemas jurídicos de los pueblos indígenas para la convivencia con el orden estatal, ha sido la oposición de este último, basada en la creencia de que los sistemas jurídicos de los grupos humanos diferenciados se hallan influenciados por una cosmovisión ancestral,

${ }^{13}$ Establecido por la Constitución vigente en su artículo 57 numeral 17. 
antítesis de modernidad (Mansilla 2004). En respuesta a esto, Zambrano Álvarez ha sabido expresar correctamente que:

La ancestralidad de los métodos de solución de conflictos que reivindican los pueblos indígenas no equivale a un congelamiento cultural en el tiempo. Se trata de un proceso evolutivo que se dio mucho antes de la implementación del régimen liberal, basado en el Estado-nación de la Francia revolucionaria. (2009: 223)

Resumiendo, los sistemas de justicia indígena más que representar un remanente arcaico y brutal de nuestras poblaciones aborígenes que no eran ni brutales, ni arcaicas-, monumentalizan la idea de agente comunicacional de los estados postmodernos, donde el sincretismo, la innovación y la evolución cognitiva son motores de la sociedad, impulsados por sujetos interculturales que conviven en su interior.

A eso habría que agregar, que muy por el contrario al estereotipo de ancestralidad, para ciertos autores como Wray (2007) y Teresa Sierra (2009) alguno de los componentes actuales del conjunto de creencias jurídicas que manejan actualmente los pueblos indígenas (juicios por jurados, resoluciones escritas, carga de la prueba, entre otras) son asimilaciones del orden jurídico estatal; lo cual resultaría peligroso, no para la comunidad exterior al entorno indígena, sino por la eventual aculturación hegemónica de la interacción cognitiva interna (Albó 2012).

Finalmente, con respecto al segundo paradigma que ataca al fenómeno indígena, es decir, su degradación conceptual a eventos de linchamiento grupal (Vega 2002); vale indicar que bajo dicha afirmación se omite observar que en el fondo los episodios de violencia desarrollados por poblaciones indígenas - que no son generalizados sino excepcionales - están provocados por la imposibilidad de administrar de un sistema autónomo de justicia, que a su vez es una derivación de las negaciones impuestas por las culturas dominantes a fin de soslayar mediante la titularidad de la decisión política el desarrollo social de comunidades diversas. Lang, sentencia perfectamente «la justicia por mano propia o linchamiento es una reacción de venganza frente a la falta de acceso a la justicia, a la falta de protección por las autoridades, lo cual los lleva a ocasionar graves violaciones de derechos humanos, llegando hasta el asesinato» (2009: 10).

Finalmente, para el análisis del segundo problema, es decir la falta de independencia comunicacional entre los subsistemas que conforman a los pueblos indígenas, debemos partir desde las ideas de Luhmann, para quien la distinción entre los subsistemas funcionales de una organización 
social dependerá de la singularidad de cada código binario que dicho subsistema utilice para analizar su interior y entorno (Luhmann 1987). Entonces, si el deber ser de una organización social es el de ser un órgano clausurado de interacción comunicacional interna, los subsistemas al interior de las sociedades indígenas requerirán también la posibilidad de autorreferencia y autogeneración.

Complementando esta línea es factible destacar al menos ocho subsistemas en el interior de las organizaciones sociales: la ciencia, la mediatización, la religión, la política, la economía, la educación, la familia y el derecho (Urteaga 2010). Cada subsistema tendría por vocación la realización de su función operativa; a saber, la ciencia buscaría diferenciar entre lo verdadero y lo falso, la familia decidirá entre lo domestico y lo ajeno, el derecho entre lo justo e injusto, etcétera, pero a su vez mantendrían cierta dependencia funcional.

Sin embargo, en el Ecuador los subsistemas que integran las poblaciones indígenas prácticamente carecen de esta facultad de autorreferencia y autogeneración, habiendo sido incluso algunos eliminado, como el caso de las religiones indígenas sustituidas por el cristianismo (León Portilla 2003) o las lenguas indígenas costeñas completamente reemplazadas por el español.

Así las cosas, a falta de ciencia (sin subordinación a los criterios de verdad de la sociedad hegemónica o los órganos estatales), economía (sin afectación de la dimensión binaria de inversión/lucro del capitalismo), mediatización (sin fines comerciales), política (sin sujeción a principios liberales o a una infraestructura centralizante), educación (sin límites aculturizantes), religión y familia propiamente indígenas, la idea de un sistema jurídico puro es sencillamente una utopía.

Finalmente, de todo lo expuesto se advierte como idea última que la posibilidad de adopción de una teoría luhmanniana para la explicación de la naturaleza de la justicia indígena seguirá siendo una pretensión meramente intelectual y formal, sin ninguna prospección material.

\section{6. ¿La vuelta a la neguentropía? una alternativa para la justicia indígena. A manera de conclusión}

Como se ha expuesto a lo largo del presente ensayo, las tesis que buscan explicar la justicia indígena son, o bien incompletas, o bien, inaplicables. De este modo, inclusive la moderna tesis de los sistemas autorreferenciales de Luhmann no ha podido escapar de una ineficacia explicativa para el fenómeno jurisdiccional indígena en el Ecuador, toda vez que, en efecto, 
era presupuesto indispensable para su aplicación, la existencia de un orden social moderno, carente de estratificaciones discriminatorias y prelaciones jerárquicas, ${ }^{14}$ lo cual no se ha podido comprobar en nuestra región hasta el día de hoy. Es así que, frente a la aparente frustración, resulta acertado volver sobre los pasos de la evolución de las teorías sociológicas del siglo $\mathrm{XX}$ que trataban de explicar la naturaleza de las organizaciones sociales, y detenernos justamente en las teorías de los sistemas sociales de primer grado, previas a los autopoiéticos, caracterizadas por su inspiración en la cibernética y la teoría de la comunicación de Habermas (Urteaga 2010).

De esta manera, podríamos observar que la idea de concebir a los pueblos indígenas como sistemas abiertos y que en vez de códigos binarios se manejen mecanismos de entropía según los cuales se mantendrían estables a través del «intercambio (energético o informacional según sea el caso) entre el sistema y el entorno» (Aragón 2011: 4), nos permite pormenorizar la actual situación de la justicia indígena en el Ecuador en el sentido de revisarla como un sistema abierto en plena construcción que mediante actos de comunicación guarda una perenne referencia con el orden jurídico ordinario, que si bien hasta ahora ha sido problemática; aplicándosele un mecanismo de neguentropía - en el sentido de ley coordinadora física- se podría regular un adecuado cierre referencial con el fin de conservar intacto su núcleo cognitivo esencial, esto es, sus prácticas ancestrales.

Esta es la conclusión a la cual abordamos, con la cual se pretende la revalorización de la justicia indígena como un sistema abierto en plena construcción, que demanda por parte de los estados para su conservación, el respeto de sus mecanismos propios de neguentropía, debiéndose abstener de pretensiones exorbitantes como las ya demostradas con tratamientos procesalistas y tesis dogmáticas que hacen depender a la justicia indígena de principios liberales o remisiones a catálogos hegemónicos. 


\section{Referencias}

Aguirre Sala, J. F. (2014). «El reconocimiento de los derechos diferenciados: el debate por las minorías oprimidas». Diálogo Filosófico 88, pp. 89-104

AlBó, X. (2012). Justicia indígena en la Bolivia plurinacional. Justicia indígena, plurinacionalidad e interculturalidad en Bolivia. La Paz: Abya Yala.

Aragón, J. M. (2011). «La teoría de sistemas autopoiéticos. Una breve introducción a una teoría radical de la sociedad». Sociología y tecnociencia, Revista Digital de Sociología del Sistema Tecnocientífico, № 1 , Vol. 2 .

Baltazar Yucailla, R. (2009). «La Justicia indígena en el Ecuador». En Espinosa Gallegos-Anda, C. y D. Caicedo Tapia (editores). Derechos Ancestrales, Justicia en Contextos Plurinacionales. Quito: Ministerio de Justicia y Derechos Humanos, pp. 451-472.

Cabodevilla, M., R. Smith y A. Toledo (2004). Tiempos de guerra: waorani contra taromenane. Quito: Abya Yala.

CANQUI, Elisa (2009). «La justicia ancestral y las mujeres: visión desde el Foro Permanente para las Cuestiones Indígenas de las Naciones Unidas». En Lang, M. Mujeres Indígenas y Justicia Ancestral. Quito: UNIFEM, pp. 57-65.

CARbonnier J. (1994). Sociologie juridique. Paris: Quadrige, PUF.

Código Orgánico General de Procesos (2015). Registro Oficial Suplemento 506 del 22 de mayo, Quito.

Constitución Política de la República del Ecuador (1998). Registro Oficial 1 del 11 de agosto, Quito.

Constitución de la RepúblicA del Ecuador (2008). Registro Oficial 449 del 20 de octubre, Quito.

Corte Constitucional de Colombia (2013). «Sentencia del 5 de diciembre de dos mil trece, T-921/13». Recuperado de: http://www.corteconstitucional. gov.co/relatoria/2013/t-921-13.htm

Corte Constitucional Del Ecuador (2014). «Sentencia del 30 de julio de 2014, 113-14-SEP-CC». Recuperado de: http://www. corteconstitucional.gob.ec/sentencias/relatoria/relatoria/ficha. php?metodo=generarFichaHtml\&caso=113-14-SEP-CC

Corte Constitucional del Ecuador (2018). «Sentencia del 4 de mayo de 2018, 126-18-SEP-CC», Recuperado de: http://portal.corteconstitucional.gob. ec:8494/FichaRelatoria.aspx?numdocumento=126-18-SEP-CC 
De Donpablo, J. (2012). Las cinco caras de la opresión y su mirada sobre las segundas generaciones de inmigrantes en los modelos de integración europea. Recuperado de: https://www.fes-sociologia.com/files/ congress/12/papers/3945.pdf

Díaz Ocampo, E. y A. Antúnez (2016). «El conflicto de competencia en la justicia indígena del Ecuador». Revista Caribeña de Ciencias Sociales, Año IV, No. 48. Recuperado de: http://www.eumed.net/rev/caribe/2016/07/justiciaindigena.html http://hdl.handle.net/20.500.11763/CARIBE-2016-07justicia-indigena

Duprat, G. (1990). Connaissance du politique. Presses Universitaries de France (PUF).

Eco, U. (1977). Tratado de Semiótica General. Barcelona: Lumen.

ElosúA, M. R. (1994). Interculturalidad y cambio educativo: Hacia comportamientos no discriminatorios. Madrid: Narcea Ediciones.

Fernández Sarasola, I. (2002). La función de gobierno en la Constitución española de 1978. Oviedo: Universidad de Oviedo.

Gómez, H. (2000). De la justicia y el poder indígena. Popayán: Editorial de la Universidad del Cauca.

GonzÁlez CaSAnova, C. (1969). Sociología de la Explotación. México: Siglo XXI.

GonzÁlez, L. D. y D. GonzÁlez LAgIER (2003). Hechos y argumentos. (Racionalidad epistemológica y prueba de los hechos en el proceso penal) (I). Jueces para la Democracia.

Honneth, A. (1996). «Reconocimiento y obligaciones morales». Revista Internacional de Filosofía Política, Vol. 8, pp. 5-17

Instituto NACional DE EstadístiCAS y Censos (2006) Censo sobre condiciones de Vida. Quito: INEC.

InSTITUTO NACIONAL DE ESTAdístiCAS Y CEnsos (2008). Censo sobre condiciones de Vida. Quito: INEC.

KymlickA, W (2009). «Derechos de las minorías en filosofía política y el derecho internacional». En Espinosa Gallegos-Anda, C. y D. Caicedo Tapia (editores). Derechos Ancestrales, Justicia en Contextos Plurinacionales. Quito: Ministerio de Justicia y Derechos Humanos, pp. 3-31.

LANG, M (2009). Mujeres Indígenas y Justicia Ancestral. Quito: UNIFEM.

León Portilla, M. (2003). Pueblos indígenas de México: autonomía y diferencia cultural. México: UNAM. 
Luhmann, N. (1973). Ilustración Sociológica y otros ensayos. Buenos Aires: Sur.

Luhmann, N. (1987). Soziale Systeme: Grundriß einer allgemeinen Theorie. Frankfurt/M.: Suhrkamp.

Mansilla, A. (2004). «El Derecho Indígena y las Pautas para la Conformación de una Línea Jurisprudencial Constitucional en Bolivia». Cuadernos Electrónicos de Filosofía del Derecho, Nㅜ 10, Santa Cruz.

Martínez, M. C. y M. C. Garros Martínez (coordinadoras) (2017). Ambiente y pueblos indígenas: Una mirada interdisciplinaria. Salta: Ediciones Universidad Católica de Salta (EUCASA).

Ministerio Coordinador de PATrimonio y UNICEF (2010). Nacionalidades y Pueblos Indígenas y políticas interculturales en Ecuador: Una mirada desde la Educación. Quito.

Mires, F. (1992). El Discurso de la Indianidad. La Cuestión Indígena en América Latina. San José de Costa Rica: Abya-Yala.

Montaña Pinto, J. (2009). La Autonomía jurídica y jurisdiccional en Colombia. En Espinosa Gallegos-Anda, C. y D. Caicedo Tapia (editores). Derechos Ancestrales, Justicia en Contextos Plurinacionales. Quito: Ministerio de Justicia y Derechos Humanos, pp. 251-295.

Montoro, A. (2007). «El funcionalismo en el Derecho: Notas sobre N. Luhmann y G. Jakobs». Anuario de Derechos Humanos, Nueva Época, Vol. 8.

Neves, M. (1996). «De la autopoiesis a la alopoiesis del derecho». DOXA. 19, pp. 403-420.

Obieta Chalbaud, J.A. de (1985). El Derecho Humano de la Autodeterminación de los Pueblos. Madrid: Tecnos.

OchoA, O. (2006). Derecho civil I: personas. Caracas: Universidad Católica Andrés Bello.

ORganización IntERnACIONAL DEL Trabajo (OIT). Oficina Regional para América Latina y el Caribe (2014). Convenio Núm. 169 de la OIT sobre pueblos indígenas y tribales en países independientes. Declaración de las Naciones Unidas sobre los Derechos de los Pueblos Indígenas. Lima: OIT/ Oficina Regional para América Latina y el Caribe.

SÁNChez Botero, E. e I. JARAmillo (2009). «La Jurisdicción especial indígena». En Espinosa Gallegos-Anda, C. y D. Caicedo Tapia (editores). Derechos Ancestrales, Justicia en Contextos Plurinacionales. Quito: Ministerio de Justicia y Derechos Humanos, pp. 125-173. 
Sierra, M. T. (2009). «Las mujeres indígenas ante la justicia comunitaria. Perspectivas desde la interculturalidad y los derechos». Desacatos, núm. 31, pp. 73-96, México.

UrteagA, E. (2010). «La teoría de sistemas de Niklas Luhmann». Contrastes. Revista Internacional de Filosofía, Vol. 15, Universidad de Málaga.

VÁsquez Luna, M. (1998). Derechos de los Pueblos Indígenas de Colombia. Bogotá: Ministerio de Interior.

VEGA, N. (2002). Justicia indígena: aportes para un debate. Quito: Abya Yala.

Wray EspinosA, A. (2002) «Justicia Indígena: Sus límites constitucionales». Iuris Dictio. Revista de Derecho. Publicación arbitrada del Colegio de Jurisprudencia de la Universidad San Francisco de Quito, Vol. 3, pp. 49-56.

Young, I. (2000). La justicia y la política de la diferencia. Madrid: Cátedra.

Yrigoyen, R. (1999). Pautas para el Reconocimiento Constitucional del Derecho Indígena y su Coordinación con el Derecho Estatal. Guatemala: Fundación Myrna Mack.

ZAMBrano ÁlvareZ, D. (2009). «Justicias ancestrales analogías y disanalogías entre sistemas jurídicos concurrentes». En Espinosa Gallegos-Anda, C. y D. Caicedo Tapia (editores). Derechos Ancestrales, Justicia en Contextos Plurinacionales. Quito: Ministerio de Justicia y Derechos Humanos, pp. 231-249. 